\title{
Measurement and interpretation of carbon dioxide fluxes in the field ${ }^{1}$
}

\author{
J. L. MONTEITH
}

Rothamsted Experimental Station, Harpenden, Herts., England

\section{Summary}

The dry-matter production of field crops can be estimated from their net uptake of carbon dioxide, and vertical profiles of $\mathrm{CO}_{2}$ concentration show that crop plants normally assimilate $\mathrm{CO}_{2}$ both from the atmosphere and from the soil. The atmospheric component can be estimated from the $\mathrm{CO}_{2}$-concentration at two heights and the wind speed at three heights above the crop; and the soil component by direct absorption in soda lime. Measurements over grass and beans at Rothamsted gave a soil $\mathrm{CO}_{2}$-production of about $0,03 \mathrm{mg} \mathrm{cm}-2 \mathrm{hr}-1$ and maximum gross rates of photosynthesis about $0,2 \mathrm{mg} \mathrm{CO} \mathrm{cm}^{-2} \mathrm{hr}-1$. In terms of total solar radiation $(0,3$ to $2 \mu)$, the efficiency of photosynthesis varied from about $1 \%$ in bright sunshine to $2 \%$ or more with cloud, agreeing well with measurements by GAASTRA on selected plants in the laboratory. An attempt to establish the complete $\mathrm{CO}_{2}$-balance for beans emphasised the importance of respiratory flux in determining dry-matter production. Conventionally assumed respiration rates are inadequate and field measurements are urgently needed.

\section{Introduction}

The rate at which the end products of photosynthesis accumulate within a plant can be estimated from the net carbon dioxide exchange between the plant and its environment without reference to the complex biochemistry of intermediate compounds or processes. Quantitatively, the synthesis of compounds other than carbohydrate may be ignored during the growth of a field crop, and the assimilation of $\mathbf{n}$ moles of $\mathrm{CO}_{2}$ assumed to produce one mole of dry matter represented by $\left(\mathrm{CH}_{2} \mathrm{O}\right)_{\mathbf{n}}$. The ratio by weight of net $\mathrm{CO}_{2}$-exchange to dry-matter production is then $44: 30$, or approximately $3: 2$.

In the laboratory, the net photosynthesis of a plant or single leaf enclosed in an illuminated chamber can be calculated from the change in $\mathrm{CO}_{2}$-concentration of a transient airstream, but great care is needed to determine the true temperature and $\mathrm{CO}_{2}$-concentration at the leaf surface. According to GaASTrA (1959), the unjustified assumption that conditions at the leaf surface and in the ambient air are the same, is partly responsible for the widely varying rates of photosynthesis reported by different workers for plants in environments that seem to be almost identical. In an extension of this method, open to similar errors of interpretation, MUSGRAve and Moss (1961) and others covered field-growing plants with plastic tents and were satisfied that the temperature and $\mathrm{CO}_{2}$-concentration in the air above the enclosed

1 Lecture held at the course "Fundamentals of dry-matter production and distribution" organized by the Royal Netherlands Society for Agricultural Sciences, Wageningen, 9th January, 1962. 
plants were similar to those of the free atmosphere at the same height. This is a necessary, but not sufficient, condition for a natural microclimate within the enclosed canopy. Further evidence is needed that artificial ventilation can simulate successfully the natural turbulent exchange of $\mathrm{CO}_{2}$, water vapour, and heat between vegetation and air flowing over it.

In principle, the flux of $\mathrm{CO}_{2}$ (or of any other gas) above a field crop can be estimated from the vertical gradient of gas concentration and an appropriate transfer coefficient, with no disturbance to the crop other than the installation of a mast to support equipment. This method was first used by ThornthwaIte and Holzman (1942) to measure water-vapour flux and was later tested and refined by PASQUiLL (1950). Application to $\mathrm{CO}_{2}$ came much later because gradients are more difficult to measure, but the development of the infra-red gas analyser (URAS) in Germany enabled HuBER (1950), TAMM and KRZYSCH (1960) and others to observe diurnal variations of $\mathrm{CO}_{2}$ gradient over growing crops. INOUE et al. (1958) and LemoN (1960) used gradients to demonstrate the diurnal variation of $\mathrm{CO}_{2}$-flux: and from records for several weeks, MonTEITH and SzEicz (1960) got encouraging agreement between meteorological estimates of $\mathrm{CO}_{2}$-transfer over a field of sugar beet, and conventional estimates from dry-matter production.

Before presenting some recent measurements over grass and beans at Rothamsted, basic principles will be reviewed briefly.

\section{Transfer theory}

By analogy with molecular diffusion, the vertical flux $F$ of $\mathrm{CO}_{2}$ in the atmosphere can be related to the vertical gradient of volume concentration $\delta \varphi / \delta z$ by the equation

$$
F=-\varrho K \delta \varphi / \delta z
$$

where $\varrho$ is the density of pure $\mathrm{CO}_{2}$ and $K$ is a transfer coefficient varying with height, wind speed, and atmospheric stability. With restrictions considered below, this equation can be integrated to give

$$
F=\varrho^{m}\left(\varphi_{1}-\varphi^{2}\right) u_{3}
$$

where $m$ is a dimensionless transport number defined by

$$
m=k^{2}\left(u_{4} / u_{3}-1\right) / \ln \frac{z_{2}-d}{z_{1}-d} \ln \frac{z_{3}-d}{z_{4}-d}
$$

and $k$ is voN KARMAN's constant $(\approx 0,41)$. In the general form of eq. (2) and (3), wind speeds $u_{4}$ and $u_{3}$ are measured at heights $z_{4}$ and $z_{3}$, and concentrations $\varphi_{2}$ and $\varphi_{1}$ at $z_{2}$ and $z_{1}$; but it is normally possible to measure concentration and speed at the same pair of heights. Determination of the zero-plane displacement $d$ (an effective crop height for turbulent exchange) requires a third velocity measurement $u_{5}$ and the graphical solution of

$$
\frac{u_{5}-u_{3}}{u_{4}-u_{3}}=\frac{\ln \left(z_{5}-d\right)-\ln \left(z_{3}-d\right)}{\ln \left(z_{4}-d\right)-\ln \left(z_{3}-d\right)}
$$

The value of $m$ may also be found from the ratio of evaporation to vapour-pressure gradient, or from the ratio of total heat transfer to wet-bulb temperature gradient (MoNTEITH and SzEICZ, 1960). 
Eq. (2), (3) and (4) are subject to two important restrictions. First, gradients of $u$ and $\varphi$ must be measured within the turbulent boundary-layer representative of the crop. The height of this layer is difficult to establish either experimentally or theoretically, but as a working rule, the upwind fetch over a uniform area should be at least 50 times as great as the maximum height of measurement above the zero plane. Second, processes of momentum and mass transfer should be governed by mechanical turbulence and should be unaffected hy vertical differences in atmospheric density through gradients of temperature. This condition, loosely referred to as "neutral stability", is normally satisfied over a freely transpiring crop by day, because vertical temperature gradients are small. Over a crop short of water, temperature may decrease rapidly with height in bright sunshine, and flux calculated from eq. (2) will then be underestimated. Given a clear sky and low wind speed at night, temperature will increase rapidly with height over any crop and eq. (2) will overestimate flux. Several empirical corrections are available but were not applied to the data given here.

Converting eq. (2) to practical units and assuming a mean temperature of $13^{\circ} \mathrm{C}$ at which $\varrho=1,9 \mathrm{mg} / \mathrm{cm}^{3}$, the flux is

$$
\begin{aligned}
& F \quad=0,68 m \quad u \quad(p 1-\phi / 2) \\
& \mathrm{mg} \mathrm{cm}{ }^{-2} \mathrm{hr}^{-1} \quad \mathrm{~m} / \mathrm{sec} \quad \text { p.p.m. }
\end{aligned}
$$

where $p$ is normally about 300 parts per million (p.p.m.) by volume. Working with a height interval of 50 to $100 \mathrm{~cm}$ above the surface of a crop, both $F$ and $m u$ are roughly of order $10^{-1}$ during daylight, and concentration differences never exceed a few parts per million.

Eq. (3) is valid only above the zero plane $(z>d$ ) and the variation of $K$ (or $m$ ) with wind speed below the zero plane is unknown. A few observations suggest that $K$ may increase by four orders of magnitude from a value close to the molecular coefficient $\left(\approx 10^{-1}\right)$ at the soil surface to approximately $10^{2}$ at the level of the zero plane (PEnman and Long, 1959) and to $10^{3}$ a few metres above the crop. This rapid change in $K$ with height confuses the visual interpretation of profiles in terms of flux. At best, diagrams such as FIGs. 2 and 3 are a useful pictorial guide to the direction of flux and to the position of $\mathrm{CO}_{2}$-sources and sinks.

\section{Flux components}

The chosen unit of flux is milligrams per hour per square centimetre of ground area. If the gross photosynthesis of a crop is $P$, and if $R_{r}$ and $R_{t}$ are the respiration of root and tops respectively, the net gain of dry matter will be proportional to $\left(P-R_{r}-R_{t}\right)$. The two sources of $\mathrm{CO}_{2}$ are the soil and the atmosphere. In the soil, the total $\mathrm{CO}_{2}$-production is $\left(R_{r}+R_{m}\right)$ where $R_{m}$ is the $\mathrm{CO}_{2}$ released by the breakdown of soil organic matter by micro-organisms, and in the steady state $\left(R_{r}+R_{m}\right)$ will be the upward flux of $\mathrm{CO}_{2}$ at the soil surface.

The flux in the air above a crop is the difference between the total COz-production by respiration in the plant/soil system and the assimilation by leaves and other aerial parts of the plant; in symbols

$$
F_{a}=R_{r}+R_{m}+R_{r}-P=\Sigma R-P
$$

Depending on whether $\Sigma R$ is greater or less than $P, F_{a}$ will be positive (directed upwards from crop to atmosphere) or negative (directed downwards). FIG. 1 shows 
Fig. 1. Idealised diurnal variation of atmospheric $\mathrm{CO}_{2}$-flux $\mathrm{Fa}$ shown by full line zsz'. Downward fluxes are values above the axis $0 o^{\prime}$. For other symbols, see text

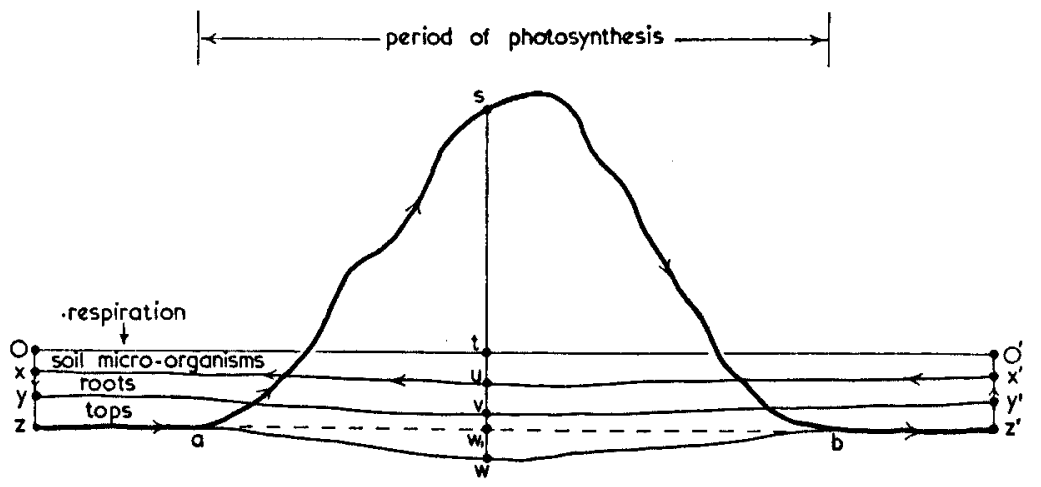

the idealised diurnal variation of $F_{a}$ (heavy line) with respect to the axis of zero flux $0 o^{\prime}$, which runs from midnight to midnight. This is the measurement from which other flux components must be deduced. For ease of presentation, the total respiratory flux $\mathrm{zz}^{\prime} \mathrm{o}^{\prime} \mathrm{O}$ is shown as the sum of three components ox, $\mathrm{xy}$ and $\mathrm{yz}$ representing $R_{m}, R_{r}$, and $R_{t}$, respectively, assumed approximately equal and with a small diurnal variation in phase with air temperature.

During the day, the downward flux from the atmosphere to the surface is st, gross photosynthesis $(P)$ is $\mathrm{sw}$ and net photosynthesis $\left(P-R_{r}-R_{t}\right)$ is su. In practice, the respiratory flux during the day tw cannot be measured, but an approximate value tw 1 is given by extrapolating the nocturnal respiratory flux as shown by the dashed line. The approximate gross photosynthesis $\mathrm{sw}_{1}$ will be a good approximation to sw, if the diurnal change in respiratory flux is small compared with photosynthesis.

The true net uptake of $\mathrm{CO}_{2}$ for $24 \mathrm{hr}$ is given by

$$
\int\left(P-R_{r}-R_{\ell}\right)=\text { asbw }-\mathrm{xux}^{\prime} \mathrm{zwz}^{\prime}=\mathrm{zsz}^{\prime} \mathrm{x}^{\prime} \mathrm{ux}
$$

which is the area enclosed by the arrowed lines (areas enclosed clockwise are positive). If $R_{m}$ is negligible compared with plant respiration, the net uptake is simply $\int F_{a}$, i.e. the area $\mathrm{zsz}^{\prime} \mathrm{o}^{\prime} \mathrm{o}$. In practice, $R_{m}$ will sometimes be a significant term in the $\mathrm{CO}_{2}$-balance, but because the activity of soil micro-organisms may depend on the presence of decaying plant material, the contributions of $R_{r}$ and $R_{m}$ to the total soil flux cannot be measured independently. At best, total soil respiration can be measured as the upflux from the soil surface (paragraph 4.2), $R_{r}$ can be estimated from root dry weight, and $R_{m}$ can be obtained by difference. In terms of quantities which can be measured or estimated, the net diurnal uptake of $\mathrm{CO}_{2}$ would then be given by

$$
\int\left(P-R_{r}-R_{t}\right)=\int F_{a}+\int\left(R_{m}+R_{r}\right)-\int R_{r}
$$

Techniques for measuring $/ F_{a}$ and $\int\left(R_{m}+R_{r}\right)$ are described in the next section. 


\section{Flux measurements}

\subsection{Atmospheric flux}

The two analysers used at Rothamsted to measure small differences of $\mathrm{CO}_{2}$-concentration were made by the Infra Red Development Company Limited, Welwyn Garden City. In operation, they are mounted in a field hut and supplied with air from within or above a crop through $50 \mathrm{~m}$ lengths of $12 \mathrm{~mm}$ diameter PVC hosepipe, continuously flushed at one litre per minute. A cotton-wool filter at each inlet keeps out insects and fungal spores, and at each outlet, air mixes in a 3-litre bottle to smooth out short-term fluctuations of $\mathrm{CO}$-concentration. Before reaching the analyser, the air is dried in tubes of silica gel and magnesium perchlorate.

MonTeith and SzEICz (1960) described the original two-point analyser. In a second system, designed to measure the $\mathrm{CO}_{2}$-profile from the soil surface upwards, air from a reference level above the crop passed continuously through the "reference" tube of an analyser with full scale deflection \pm 10 p.p.m. In the first minute of a sixminute cycle, this air flowed through the "analysis" tube too to establish zero; and in each of the five following minutes, air from five other levels was switched through the "analysis" tube in sequence. The sampling programme was controlled by a six-point thread recorder through a set of mercury switches and solenoidoperated valves. For simultaneous measurement of absolute $\mathrm{CO}_{2}$, the "reference" tube of the two-point analyser was flushed with air of known concentration from a cylinder and the sensitivity was decreased to \pm 100 p.p.m.

On the charts, hourly averages of concentration difference were read by visual estimation, using a plastic cursor, with an accuracy that increased with increasing smoothness of the signal. The reading error was normally about $\pm 0,05$ p.p.m. with the two-point analyser on its sensitive range and $\pm 0,2$ p.p.m. with the six-point analyser, rising to about five times these values with very irregular traces.

Wind speed was measured, usually at the same height as the inlets, with Sheppard cup anemometers modified by LONG (1957) to record run-of-wind, and as the stopping speed was about $20 \mathrm{~cm}$ per sec, mean hourly wind speeds below $50 \mathrm{~cm}$ per sec were subject to error because of intermittent stopping. The transport number $m$ was determined from short periods of about a week within which the crop height could be treated as constant. Mean daily values of $u_{5}, u_{4}$ and $u_{3}$ were used to find $d$ because there was evidence that departures from neutral stability were serious only on clear, calm nights when the run-of-wind did not contribute significantly to the shape of the mean daily profile. Mean values of $m$ for each period of growth were then found from the daily mean values of $d$ and $u_{4} / u_{3}$ (eq. 3). Flux was given by the product of transport number, mean hourly wind speed and mean hourly concentration difference (eq. 5) after allowing half-an-hour for the transit of air from the inlets to the analyser.

Hourly mean intensities of solar radiation were estimated from the records of a Kipp solarimeter on the nearby laboratory roof. In cloudless weather, these values could be determined to about $\pm 0,005 \mathrm{cal} \mathrm{cm}^{-2} \mathrm{~min}^{-1}$, but with the wildly fluctuating readings characteristic of intermittent cloud, the estimation error may have reached $\pm 0,05 \mathrm{cal} \mathrm{cm}^{-2} \mathrm{~min}^{-1}$.

\subsection{Soil f lux}

The relatively high concentrations of $\mathrm{CO}_{2}$ found in soil atmospheres $\left(10^{3}\right.$ to $10^{4}$ p.p.m.) imply that the main resistance to upward diffusion is met within the soil 
pores and that the resistance of the air layer immediately above the soil is negligible. When soil is covered by a container within which the $\mathrm{CO}_{2}$-concentration is maintained at 300 p.p.m. or less, the rate at which $\mathrm{CO}_{2}$ is released within the container should be similar to the upflux of $\mathrm{CO}_{2}$ into the free atmosphere. The production of $\mathrm{CO}_{2}$ within such a container can be measured by volumetric analysis (LUNDEGARDH; 1927) or with an infra-red analyser (KoEPF, 1953), but the method is probably too crude to justify refinement. At Rothamsted, Dr. K. YABuki got reproducible measurements by exposing a dish of soda lime beneath an inverted glass tank with an area of $400 \mathrm{~cm}^{2}$. The soda lime was dried and weighed before and after an exposure of two or three days and the mean flux for the period was determined from the weight increase. It is hoped to publish a fuller account of this work elsewhere.

\section{Interpretation of profiles}

In May, 1961 the absolute concentration at 1,6 m over grass (Timothy and Meadow Fescue) was recorded with the two-point analyser, and the concentration differences between $1,6 \mathrm{~m}$ and five lower levels with the six-point analyser. Combination of the records gave the absolute concentration at each height, and for May 24-25 the smooth curves of FIG. 2 were drawn to show the diurnal change in profile shape.

FIG. 2. $\mathrm{CO}_{2}$ profiles in and above long grass, 24-25 May, 1961

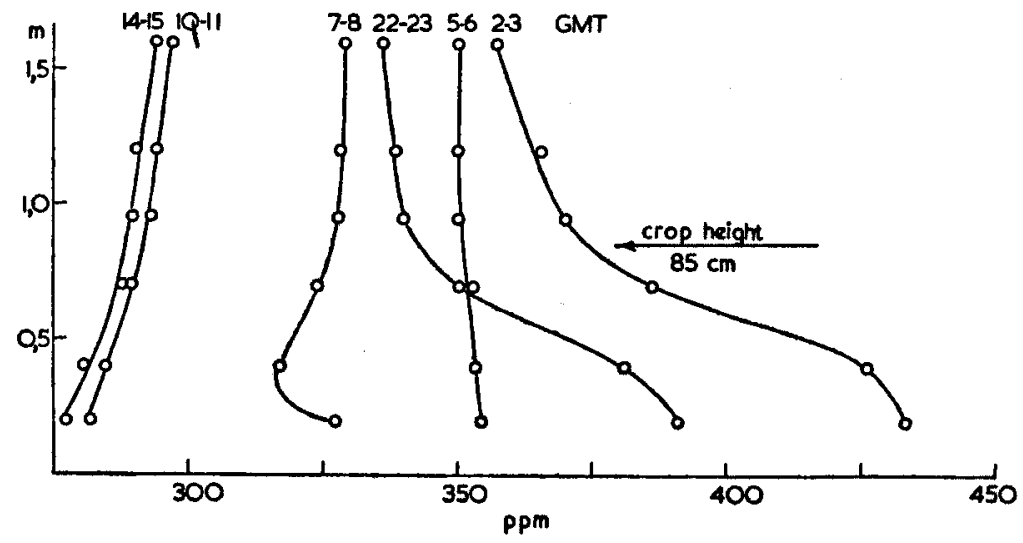

The change in absolute concentration is largest immediately above the soil surface, but even at $1,6 \mathrm{~m}$ it varies (typically) between 290 and 360 p.p.m. The existence of a diurnal $\mathrm{CO}_{2}$-cycle over vegetation is ignored in much published work on the mean concentration in the free atmosphere, and this may partly explain the wide scatter in values reported by different observers (BucH, 1958). From 10 to 11, concentration increased with height above the lowest observation level. The corresponding downward flux shows that, in the mean, leaf assimilation exceeded respiration at least down to $20 \mathrm{~cm}$, implying an efficient vertical distribution of light. Four hours later (14 to 15) profile shape was unchanged, but the absolute level was slightly lower, suggesting a small decrease in atmospheric $\mathrm{CO}_{2}$ over the countryside as a whole. After dark (22 to 23) $\mathrm{CO}_{2}$ decreased with height from $20 \mathrm{~cm}$ upwards 
showing that the crop and soil together were behaving as a source, and displacement of the profile to the right later in the night (2 to 3 ) reflects accumulation of $\mathrm{CO}_{2}$ in the lower atmosphere. Shortly after sunrise (5 to 6) the atmospheric gradient was almost zero, showing that the release of $\mathrm{CO}_{2}$ from the soil was equal to net photosynthesis by leaves; and botween 7 and 8 the profile developed a minimum at $40 \mathrm{~cm}$. Because there can be no flux when the gradient is zero, this minimum shows that net photosynthesis above $40 \mathrm{~cm}$ was equal to the downward atmospheric flux, and that below $40 \mathrm{~cm}$ it was equal to the upward flux from the soil.

The last profile for grass is similar to those observed throughout the day in beans (Vicia vulgaris) shown in FIG. 3 (note the arbitrary horizontal scale). The upwind fetch was insufficient to bring the $2 \mathrm{~m}$ level within the crop boundary layer so that gradients between 1,5 and $2 \mathrm{~m}$ are unrepresentative of the exchange, but gradients between 0,9 and $1,5 \mathrm{~m}$ show the diurnal flux cycle clearly. The height of minimum concentration is shown at about $90 \mathrm{~cm}$, but plausible curves could be drawn with the minimum at any level down to $75 \mathrm{~cm}$. Whatever the precise level of the minimum, the assimilation of atmospheric $\mathrm{CO}_{2}$ was confined to the upper leaf layers, and lower leaves were supplied with $\mathrm{CO}_{2}$ from the soil. An alternative interpretaan is that leaves lower than $75 \mathrm{~cm}$ were below the light-compensation point and were therefore acting as $\mathrm{CO}$-sources, but light intensities recorded within the canopy do not support this hypothesis.

FIG. 3. $\mathrm{CO}_{2}$ profiles in and above beans, 21 June, 1961

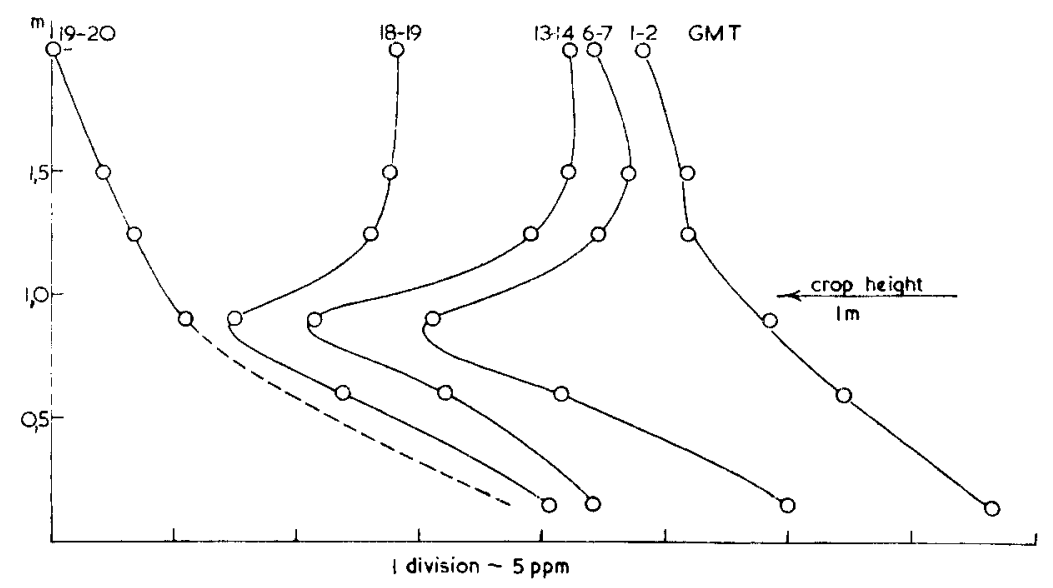

\section{Interpretration of fluxes}

FIG. 4 shows the variation of $\mathrm{CO}_{2}$-flux and solar radiation for a period of 72 hours in May 1961. As the fluxes were uncorrected for atmospheric stability, many of the nocturnal values shown are too large to be real. Inspection of other weather records showed that the correction would be small for a few hours after midnight on 26 May and for a few hours before midnight on 27 May when the mean hourly flux was $0,08 \mathrm{mg} \mathrm{cm}^{-2} \mathrm{hr}^{-1}$, and this was chosen as the mean level of respiration shown by the dashed line (corresponding to $\mathrm{zWz}^{\prime}$ in FIG. 1). Using this line as a base, the gross photosynthesis during the day ( $\mathrm{sw}_{1}$ in FIG. 1) was calculated for each 
hour and converted into energy units assuming that the heat of combustion of $1 \mathrm{mg}$ of carbohydrate was 3,7 cal. To obtain an efficiency figure, this stored energy was expressed as a percentage of total solar radiation. For efficiency in terms of visible radiation in the wavelength range 0,4 to $0,7 \mu$ (containing approximately $40 \%$ of the energy in the solar spectrum), the units at the top left-hand corner of FIo. 4 should be multiplied by 2,5. On 26 and 27 May, efficiency varied inversely with radiation, falling to about $1 \%$ in strong sunshine and increasing to 2 or $3 \%$ with cloud and with lower intensities of direct radiation in the early morning and late afternoon. GAASTRA (1958) gave similar figures for sugar beet in the laboratory and in the field. In conflict with FIG. 4, Moss et al. (1961) found that the efficiency of maize was about $3 \%$ of total radiation in bright sunshine and about $2 \%$ with heavy cloud, a variation which is difficult to reconcile with the light-response curves of GAASTRA and other workers.

Frg. 4. Diurnal variation of $\mathrm{CO}_{2}$-flux over grass and total solar radiation in wavelength range $0,3-2 \mu$. Dashed line is estimated respiration for calculating gross photosynthesis, and hence photosynthetic efficiency (top curves)

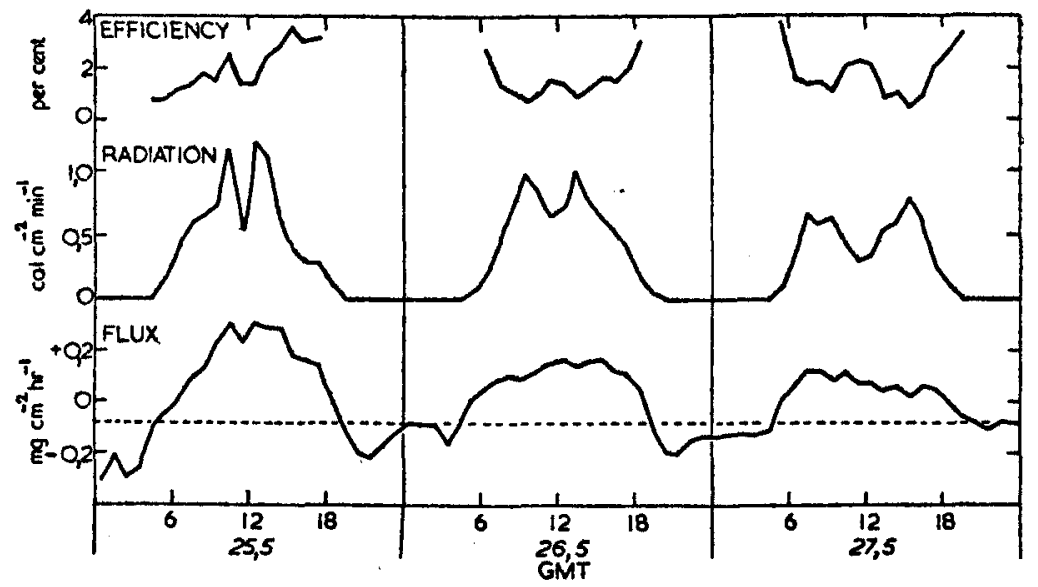

On 25 May, fluxes are higher than on the two later days, although radiation is similar, and the diurnal variation of efficiency is improbable. The $\mathrm{CO}_{2}$-records were examined for possible evidence of misbehaviour in the analyser but no fault was detected and the record has been presented as an admission of technical imperfections whose cause is still being sought.

FIG. 5 shows the gross assimilation for the two later days plotted against mean hourly radiation intensity. For comparison, the dashed line was obtained by Dr. GAASTRA from laboratory measurements on grass transplanted from the field into pots and brought indoors when required. The light source for these measurements was a mercury-vapour lamp giving a maximum working intensity of about 0,2 cal $\mathrm{cm}^{-2} \mathrm{~min}^{-1}$ in the range 0,4 to $0,7 \mu$ and, for conversion to the units of FIG. 5, this was assumed equivalent to a solar radiation intensity of $0,5 \mathrm{cal} \mathrm{cm}^{-2} \mathrm{~min}^{-1}$. The dashed line shows the assimilation of a single horizontal leaf layer. Following DE WIT (1959) with the assumption that $10 \%$ of photosynthetically useful light is transmitted by such a layer, the full curve shows the total assimilation from two layers of 
Fig. 5. Variation of gross photosynthesis of grass with total solar radiation: full points, 26 May, open points, 27 May, 1961. Dashed line is laboratory response for single leaf layer; full line is estimated laboratory response for two leaf layers

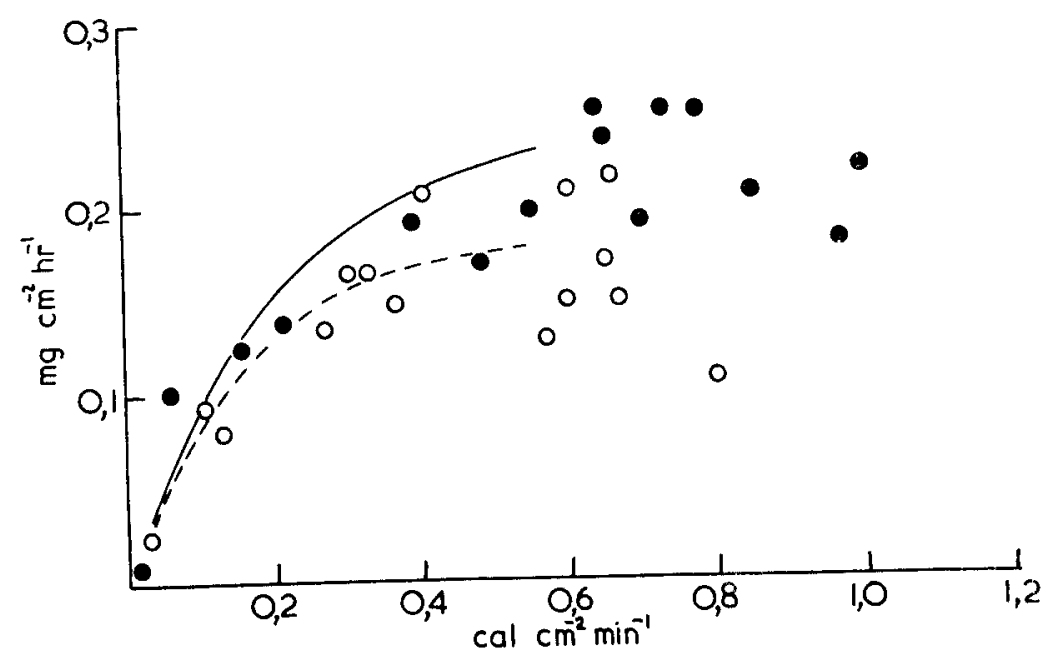

leaves, the second using all the radiation transmitted by the first. The curve given by this simple model agrees well with the field observations but the scatter of points at high radiation intensities is typical of meteorological estimates of assimilation and deserves comment. The effect may be real: the photosynthetic capacity of fieldgrown crops may vary irregularly with the sequence of weather from day to day or even from hour to hour: or the scatter may be an artefact produced by changes in atmospheric stability or by some other failure of the theoretical flux/gradient relationship.

FIG. 6 is a similar diagram for beans. On 21 June (cf. FIG. 3) the crop was growing vigorously upwards at about $3,5 \mathrm{~cm} /$ day and with a soil moisture deficit of $4 \mathrm{~cm}$, there was no physiological indication of water stress. Towards the end of July, vertical growth had stopped but seed pods developed to about $40 \%$ of total fresh weight. The soil-moisture deficit was $10 \mathrm{~cm}$ and many of the younger leaves wilted in bright sunshine. On neither day could the respiratory level be determined from the apparent nocturnal flux, which was seriously overestimated. In June, a respiration of $0,06 \mathrm{mg} \mathrm{cm}^{-2} \mathrm{hr}^{-1}$ was estimated from the flux on other nights and the corresponding level in July was $0,12 \mathrm{mg} \mathrm{cm}^{-2} \mathrm{hr}^{-1}$.

On 21 June, solar radiation was exceptionally great because of reflection from small amounts of cloud and at mid-day the mean intensity for the hour reached 1,35 cal $\mathrm{cm}^{-2} \mathrm{~min}^{-1}$ compared with the normal midsummer maximum of about $1,25 \mathrm{cal} \mathrm{cm}^{-2}$ $\mathrm{min}^{-1}$. The corresponding flux curve shows the effect of light saturation at about $0,4 \mathrm{cal} \mathrm{cm}^{-2} \mathrm{~min}^{-1}$. The variation of efficiency with light intensity follows the pattern for the grass with somewhat higher mid-day values. On $25 \mathrm{July}$, gross photosynthesis and efficiency are both smaller than in June. because older leaves were less efficient or because stomatal resistance increased with increasing soil moisture stress. 


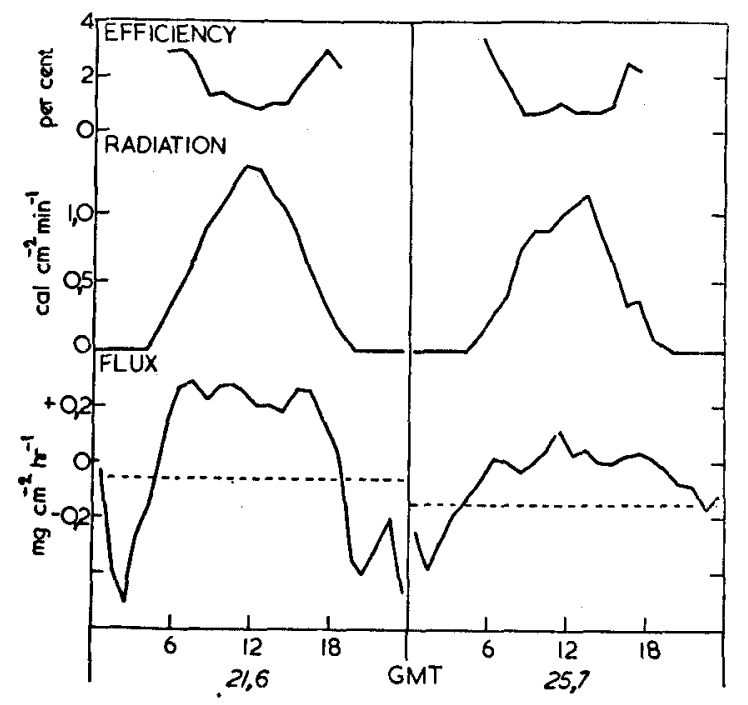

FIG. 6

Diurnal variation of $\mathrm{CO}_{2}$ flux over beans and total solar radiation (see FIG. 4)

FIG. 7 shows gross photosynthesis plotted against light intensity for both days. The dashed curve was calculated from laboratory measurements at the end of July on field grown pot-plants, making the assumption of two leaf layers. Comparable measurements were not made in June, but the full curve is for young plants, sown in pots in July and brought into the laboratory in September. This second curve shows higher levels of photosynthesis than for grass in FIG. 5, consistent with differences of flux observed in the field.

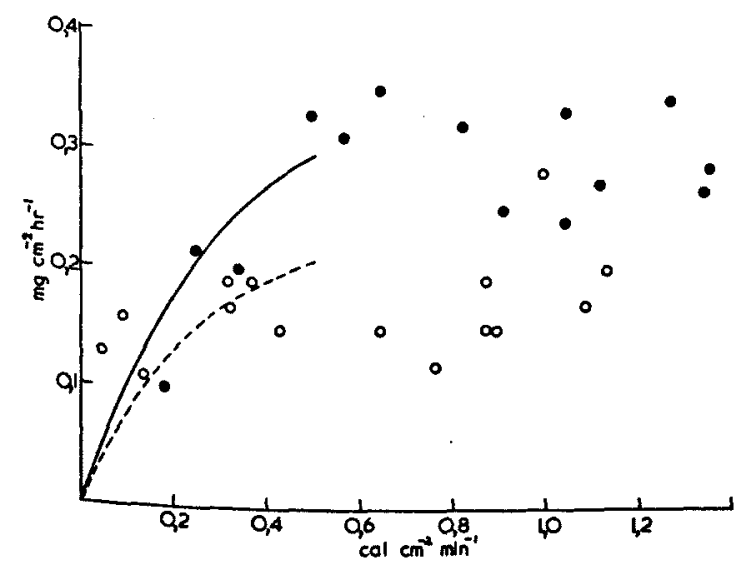

\section{FIG. 7}

Variation of gross photosynthesis of beans with total solar radiation: full points, 21 June, open points 25 July, 1961. Dashed line is laboratory curve for mature beans (two leaf layers) and full line is laboratory curve for young beans (two leaf layers)

\section{The $\mathrm{CO}_{2}$-balance of beans}

Given the exchange of $\mathrm{CO}_{2}$ between crop and atmosphere, the respiration of different plant organs, and of micro-organisms in the soil, the net uptake of $\mathrm{CO}_{2}$ by a crop can be calculated in two ways corresponding to the two sides of eq. (7) and can then be compared with a third, independent estimate from the rate of dry-matter production. Attempts to produce $\mathrm{CO}_{2}$-balance sheets are still immature, but the TABLE gives two examples to show their usefulness. Gross photosynthesis and net uptake 
TABLE. $\mathrm{CO}_{2}$-flux components for beans $\left(\mathrm{mg} \mathrm{cm}-2 \mathrm{day}^{-1}\right)$

\begin{tabular}{|c|c|c|}
\hline & 21 June, 1961 & $25 \mathrm{July}, 1961$ \\
\hline Gross photosynthesis & 3,8 & 2,0 \\
\hline Respiration: Tops & 0,7 & 2,9 \\
\hline Roots & 0,3 & 0,3 \\
\hline Net photosynthesis. & 2,8 & $-1,2$ \\
\hline Net uptake from atmosphere & 2,3 & $-0,4$ \\
\hline Uptake from respiration by soil micro-organisms & 0,3 & 0,2 \\
\hline Total net uptake $\ldots \ldots \ldots \ldots \ldots \ldots \ldots \ldots$ & 2,6 & $-0,2$ \\
\hline $\begin{array}{l}\text { Net uptake estimated from mean dry matter } \ldots \\
\text { production } \ldots \ldots\end{array}$ & $\begin{array}{c}2,1 \pm 0,4 \\
(16-23 \text { June })\end{array}$ & $\begin{array}{c}0,4 \pm 0,6 \\
(21-28 \text { July })\end{array}$ \\
\hline
\end{tabular}

of atmosphere $\mathrm{CO}_{2}$ were found from meteorological data, plant respiration from laboratory measurements by Dr. GAASTRA, and the respiration of soil micro-organisms from the soil $\mathrm{CO}_{2}$-flux, less root respiration. Mean dry-matter production was found from sampling. Each week, three adjacent plants were removed from ten randomly chosen positions on the field and the standard error was calculated from the weights of the ten sub-samples.

Agreement between the three estimates is good for the first period when both the gross and net photosynthesis were large. In the second period, the respiratory loss from the tops, mainly from pods, was greater than gross photosynthesis, giving a net loss of $1,2 \mathrm{mg} \mathrm{cm}^{-2} \mathrm{day}^{-1}$, but from the second estimate, the loss was only 0,2 $\mathrm{mg} \mathrm{cm} \mathrm{cm}^{-2} \mathrm{day}^{-1}$. Agreement of these two estimates depends effectively on the similarity of values for plant respiration determined directly in the laboratory and indirectly from the nocturnal respiratory flux in the field. As both these measurements may have errors of $\pm 20 \%$ or more, a difference of $1 \mathrm{mg} \mathrm{cm}^{-2} \mathrm{day}^{-1}$, or $30 \%$ of plant respiration, is consistent with experimental error. The corresponding dry-matter determination was small and positive but may differ from the other two estimates if 25 July was not representative of the sampling period.

The TABLE emphasises the importance of plant respiration in determining rates of dry-matter production. The decrease in gross photosynthesis between June and July is less than the increase of respiration following the development of pods. Generalizing from this limited evidence, seasonal changes in dry-matter production may often be governed by changes in respiration rate rather than by the variation of photosynthetic potential with solar radiation and other weather factors. This may be one reason why WATSON (1947) found no significant correlation between crop growth and radiation using mean values for periods of a week or more, whereas the hourly values of $\mathrm{CO}_{2}$-flux reported here are strongly correlated with radiation. As a corollary, the successful comparison of dry-matter production with estimates of potential photosynthesis will often depend on a realistic estimate of respiration. Unfortunately, field measurements of respiration rate are very rare and many workers have assumed that respiration is some fixed fraction, about $20 \%$, of gross photosynthesis. The TABLE shows that this fraction may sometimes be much higher and, as further evidence, FIG. 8 compares daily values of DE WIT's (1954) potential photosynthesis with the photosynthesis of a mature stand of sugar beet obtained from measurements of $\mathrm{CO}_{2}$-flux. The crop completely covered the ground and was adequately supplied with water, satisfying the two main conditions for photosynthesis 


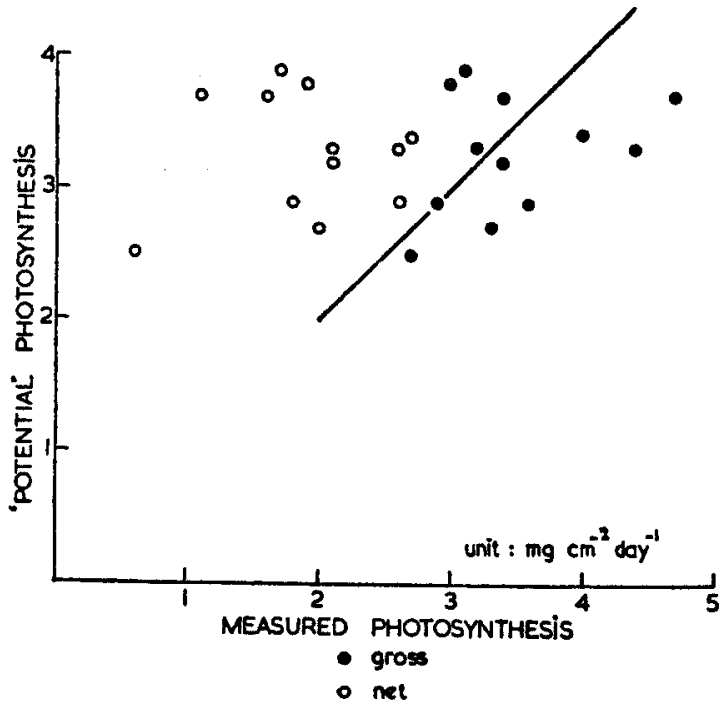

FIG. 8

Daily values of "potential" photosynthesis calculated from DE WIT (1959), and measured gross and net photosynthesis of sugar beet from flux measurements (MoNTEITH and SzEICZ, 1960), with line of unit slope

at the potential rate. Agreement between daily rates of potential and measured gross photosynthesis is good: but because measured respiration is about $45 \%$ of gross photosynthesis, mean net photosynthesis is only. $55 \%$ of the mean potential rate.

\section{Conclusions}

The application of the infra-red gas analyser to the measurement of $\mathrm{CO}_{2}$-flux in the field enables the dependence of crop growth on weather to be studied in much greater detail than by conventional sampling. The uptake of atmospheric $\mathrm{CO}_{2}$ can be studied hour by hour, and from contemporary measurements of soil flux and of the respiration of different plant organs, the factors determining the strength of $\mathrm{CO}_{2}$-sources and sinks in the soil/plant system can be examined separately.

Ultimately, a more complete picture of the $\mathrm{CO}_{2}$-balance of agricultural crops may suggest improvements in methods of cultivation or may guide in the selection of more efficient species.

At present, the main disadvantages of the meteorological estimation of $\mathrm{CO}_{2}$-flux are:

1. the expense of equipment (about 10.000 guilders or $£ 1.000$ );

2. the difficulty of maintaining accurate records of $\mathrm{CO}_{2}$-gradient over long periods;

3. uncertainty about the relationship between gradient and flux in the presence of temperature gradients;

4. probably a consequence of 2 . and 3 , the occasional appearance of absurd values of flux.

\section{ACKNOWLEDGEMENTS}

It is a pleasure to acknowledge the co-operation of two visitors to Rothamsted: Dr. K. YABUKI who made soil-flux measurements; and Dr. P. GAASTRA whose laboratory measurements of photosynthesis and respiration stimulated the discussion of $\mathrm{CO}_{2}$-balance in section 7. I am also most grateful to $\mathrm{Mr}$. I. F. LoNG for wind measurements and to Mr. G. SzEICz who was responsible for much of the field work and subsequent analysis. 
Buch, K.

GaAstra, P.

HuBER, B.

INoue, E., N. TANI, K. IMAI, and S. Isobe

KOEPF, $\mathbf{H}$.

LEMON, E. R.

LONG, I. F.

\section{LUNDEGARDH, $\mathrm{H}$.}

Monteith, J. L., and G. SzEICZ

Moss, D. N., R. B. MusGRAVE and E. R. LEMON

Musgrave, R. B., and D. N. Moss

Pasquill, F.

Penman, H. L., and I. F. LONG

TAMM, E., and G. KRZYSCH

WATSON, D. J.

WIT, C. T. DE

\section{LITERATURE}

1958 Das Kohlendioxyd in der atmosphärischen Luft. Handbuch der Pflanzenphysiologie. Springer-Verlag, Berlin. Bd 5, 12-23.

1958 Light energy conversion in field crops in comparison with the photosynthetic efficiency under laboratory conditions. Meded. Landb.hogesch. Wageningen. 58 (4) 1-12.

1959 Photosynthesis of crop plants as influenced by light, carbon dioxide, temperature, and stomatal diffusion resistance. $\mathbf{M e d e d}$. Landb.hogesch. Wageningen. 59 (13) 1-68.

1952 Der Einfluss der Vegetation auf die Schwankungen des $\mathrm{CO}_{2-}$ Gehaltes der Atmosphäre. Arch. Met. Wien. B 4, 154.

1958 The aerodynamic measurement of photosynthesis over the wheatfield. J. Agric. Meteor. 13, 121.

1953 Die Verwendung des URAS für die Registrierung der Bodenatmung im Freiland. Land. Forsch. 5, 54.

1960 Photosynthesis under field conditions, II. Agronomy Jour $52,697$.

1957 Instruments for micrometeorology. Quart. Jour. Roy. Met. Soc. 83, 202.

1927 Carbon dioxide evolution of soil and crop growth. Soil Sci. $23,417$.

1960 The carbon dioxide flux over a field of sugar beet. Quart. Jour. Roy. Met. Soc. 86, 205-214.

1961 Photosynthesis under field conditions, III. Crop Sci. 1, 83.

1961 Photosynthesis under field conditions, I. Crop Sci. 1, 37.

1950 Some further considerations of the measurement of evaporation. Quart. Jour. Roy. Met. Soc. 76, 287.

1960 Weather in wheat. Quart. Jour. Roy. Met. Soc. 86, 16.

1960 Zum Verlauf des $\mathrm{CO}_{2}$-Gehaltes der Luft. Z. Acker- u. Pfl. Bau. 112, 377.

1947 Comparative physiological studies on the growth of field crops, I. Ann. Bot. 11, 41.

1959 Potential photosynthesis of crop surfaces. Neth. Jour. agric. Sci. $7,141$. 